\title{
Factors Hindering Formal and Informal Nursing Mentorship Programs in Kenyan Public Universities
}

\author{
Sherry Oluchina ${ }^{1}$, Lucy K. Gitonga ${ }^{2}$ \\ ${ }^{1}$ School of Nursing, Jomokenyatta University of Agriculture and Technology, Nairobi, Kenya \\ ${ }^{2}$ Department of Nursing, Chuka University, Nairobi, Kenya
}

Email address:

gitonga30@yahoo.com

\section{To cite this article:}

Sherry Oluchina, Lucy K. Gitonga. Factors Hindering Formal and Informal Nursing Mentorship Programs in Kenyan Public Universities. American Journal of Health Research. Vol. 4, No. 2, 2016, pp. 23-29. doi: 10.11648/j.ajhr.20160402.12

Received: February 24, 2016; Accepted: March 4, 2016; Published: March 31, 2016

\begin{abstract}
Introdruction: Mentorship was a one to one reciprocal relationship between a more experienced and knowledgeable mentor and a less experienced mentee. Objective: The study aim was to evaluate barriers of formal and informal nursing mentorship programs in Kenya public universities. Methods: The study utilized a cross-sectional study design. It used both qualitative and quantitative methods in data collection where 305 mentees and mentors participated. Simple random, purposive and snowball non probability samplings were used to select participants. Exploratory and thematic content analyses were done. Results: Barriers encountered were work overload, lack of recognition of mentors, roles of mentors and mentees not clear, lack of support from mentors and institutions, unavailability of mentors, unfit mentor-mentee ratio, inappropriate mentor-mentee matching, unfit personality traits and inadequate time. Recommendations: The study therefore recommended that, all the stakeholders should be encouraged to evaluate nursing mentorship programs in institutions' of higher learning.
\end{abstract}

Keywords: Evaluation, Mentees, Mentors, Mentorship

\section{Introduction}

Over the past several years, nursing programs had been called upon to restructure education programs to better prepare nursing students for increasingly complex and rapidly changing health care environments. According to Coleen et al (2010), "Nursing education must be redesigned to prepare student nurses for new responsibilities and challenges in health care environments." To accomplish this, the practice-education gap must be addressed by major shifts in teaching methods (Eby et al., 2010). One major shift in teaching methods was mentorship programs. For mentorship programs to exist there should be a mentor and mentee. A mentor was a person who had expertise in the areas of need identified by the mentee and was able to share the wisdom in a nurturing way. A mentee was someone seeking guidance in developing specific competencies, self awareness and skills in early intervention (Bozemanand feeney 2008).

Elements of mentorship included giving advice, psychosocial support, role modelling, career advising or counselling, cultivating the intellect of mentee, and varying help given to meet the needs of the mentee over time (Williamson and Humphrey 2005). Mentorship provided guided skill perfection by modelling proficiency, providing corrective feedback and maintaining confidence in mentees' abilities.

Mentorship programs took a variety of forms. In some cases, formal mentorship programs were administered where students were assigned to mentors. Formal mentorship programs were where relationships were assigned in relation with organizational mentorship programs structures (Coleen 2010). In others, students and mentors develop relationships "naturally" with no formal structure or support from the institutions' administration (Coleen 2010.).

Mentorship programs commenced in the year 1985 worldwide, but in Kenya in 2000. Considering nursing programs in Kenyan public universities, KU was the first public university to roll out formal mentorship program on 21st June, 2006. Since the initiation of mentorship programs in nursing programs in Kenyan public universities, they have not been evaluated to determine barriers of nursing 
mentorship programs. As a result of this, necessary amendments had not been done and mentees received ineffective and nonsystematic support during their practice, which hindered their nursing profession growth and development (Grealish 2009.). This also inhibited mentees coordination of care within the unique context of general practice and as a result clients ended up suffering on their hands and those who had acute illness ended up with chronic illness (Grealish 2009.). The clients then ended up staying in hospitals for a long duration of time and this posed challenges to their economic status (Grealish 2009.).

Furthermore, there was lack of understanding of mentees' needs during mentorship programs which affected their learning dynamics (Gagen \& Bowie 2005.). Mentees had needs which needed to be attended to, to enhance smooth running of the mentorship programs, for example availability of adequate infrastructure and environment. Non awareness of these needs made mentees to suffer in the complex landscape of academics as they struggled to cope with its unique philosophies (Gagen \& Bowie 2005). In addition, mentees' suffered from vast amount of stimuli particularly within the community setting where clinical environment was difficult to control. These stimuli were interpersonal relationships, staffand patient attitudes, physical structure of the settings, lack of knowledge and skills, and difficulty in handling the gap between on-the-job reality and the training they received (Grealish 2009.).

On part of mentors, this caused increased level of anxiety, lowered level of self confidence, impaired development of technical skills, decreased personal and professional growth, and decreased cooperative learning and critical thinking (Gagen \& Bowie 2005). Also it caused mentors to provide inadequate psychosocial support and career development functions to mentees that lowered quality of their learning process (Grealish 2009). Therefore, there was need to evaluate barriers of nursing mentorship programs in Kenyan public universities.

\section{Materials and Methods}

\subsection{Study Design, Area and Population}

This was a cross sectional study design.It was carried out in KU, UON, MMUST, KNH (Kenyatta National Hospital) and KPGH (Kakamega Provincial General Hospital). The study population comprised of mentors (lectures and nurses) and mentees in the above institutions.

\subsection{Sample Size}

The sample size formula of Cochran (1977), was used to calculate the sample size as follows:

$$
\begin{gathered}
n_{0}=\frac{(\mathrm{t})^{2} *(\mathrm{P})(\mathrm{q})}{(\mathrm{d})^{2}} \\
n_{0}=\frac{(1.96)^{2}(.5)(.5)}{(.05)^{2}}=384
\end{gathered}
$$

Where

$\mathrm{t}=$ value for selected alpha level of.025 in each tail $=1.96$

$(\mathrm{p})(\mathrm{q})=$ estimate of variance $=.25$ (maximum possible proportion $(.5) * 1$-maximum possible proportion (.5) produces maximum possible sample size).

$\mathrm{d}=$ acceptable margin of error for proportion being estimated $=.05$

Therefore, for a population of 1,000, the required sample size was 384 . However, since this sample size exceeded $5 \%$ of the population, Cochran (1977), correction formula was used to calculate the final sample size. These calculations were as follows:

$$
\begin{gathered}
n_{1}=\frac{n_{0}}{\left(1+n_{0} / \text { Population }\right)} \\
n_{1}=\frac{384}{(1+384 / 1000)}=277
\end{gathered}
$$

Where population size $=1,000$

Where $\mathrm{n}_{0}=$ required return sample size according to Cochran's formula $=384$

Where $\mathrm{n}_{1}=$ required return sample size because sample $>$ $5 \%$ of population

The calculation result in a minimum returned sample size of 277 .

Attribution $10 \%$ for the sample size

$10 / 100 * 277=28$

$28+277=305$

Then probability proportionate to sample was used to calculate sample size for lecturer-mentors, nurse-mentors and mentees as follows using their population sizes (KNH and Kakamega provincial hospital registry data 2012 and MMUST, KU and UON registry data 2012) (Table 1).

Table 1. Probability proportionate to sample size used to calculate sample size for lecturer-mentors, nurse-mentors and mentees.

\begin{tabular}{lll}
\hline Sampling unit & Population size & Sample size \\
\hline Lecture-Mentors & 150 & $150 / 1000 * 305=46$ \\
Mentees & 350 & $350 / 1000 * 305=106$ \\
Nurses-Mentors & 500 & $500 / 1000 * 305=153$ \\
\hline
\end{tabular}

\subsection{Sampling Procedure}

Simple random probability, purposive and snowball non probability sampling methods were utilized. In this study, simple random sampling helped the researcher to randomly select two Kenya public universities (UON and MMUST) offering informal mentorship programs and respondents who were to provide quantitative data who filled the questionnaires.

In this study, first, purposive sampling was used to sample $\mathrm{KU}$ because they had formal mentorship program; KNH and KPGH because they were the largest hospitals where nursing students from the above universities went for their clinical practice that was, nursing students from UON and KU went to $\mathrm{KNH}$ and those from MMUST went to KPGH; and nursing program from UON, KU and MMUST because this was the program in the universities where the study was to focus.Secondly, purposive sampling was used to select $3^{\text {rd }}$ 
and $4^{\text {th }}$ year Bachelor of Science in Nursing $(\mathrm{BscN})$ students (mentees) as the group to participate in the study. This was because they had been in mentorship program for more than two years. Thirdly, it was used to select initial mentees in $3^{\text {rd }}$ and $4^{\text {th }}$ year who were informative about nursing mentorship program, who participated in naming other mentees who were to participate in focus group discussion using snowball non probability sampling. For qualitative data, mentees were purposively selected outside the group of mentees who responded to the questionnaire.

\subsection{Criteria of Inclusion}

All mentees who were doing $\mathrm{BscN}$ in $\mathrm{KU}$, UON and MMUST and were in their third and fourth year; Lecturers in health sciences programs and nurse mentors in the above institutions mentoring the third and fourth year $\mathrm{BscN}$ students; mentees and mentors who were in the above institutions within the study period and who gave consent to participate in the research.

\subsection{Study Tools}

The tool used for quantitative data collection was a semistructured questionnaire. Qualitative data was collected using focus group interview guide.

\subsection{Selection and Training of Enumerators}

Purposive and snowball non probability sampling was used to select fifteen and five $\mathrm{BscN}$ interns in $\mathrm{KNH}$ and KPGH respectively as enumerators. The enumerators were trained prior to data collection.

\subsection{Pre-testing of Research Tools}

The questionnaire and the focus group discussion guide were corrected after pilot study that was done in Moi University School of nursing and Moi Teaching and Referral Hospital (MTRH).

\subsection{Data Collection}

Data collection was done using both quantitative and qualitative methods. They included cross-sectional survey and focus group interview.

\subsection{Data Analysis}

Exploratory data analysiswas used to summarize quantitative data. This was done to summarize data in terms of frequencies, percentages and proportions. For qualitative data analysis, the following steps were followed: reception of cassette and tape recorders, data transcription, data organization, open, axial and selective coding, and evaluation of information selected.

\subsection{Ethical Considerations}

Ethical approval from $\mathrm{KNH} / \mathrm{UON}$ and Great Lake University of Kisumu (GLUK) institutional ethical committee was sorted. Informed consent was also sorted from the participants.

\section{Results}

Participants described various barriers of nursing mentorship programs. These were categorized into themes. A total of ten themes were identified as barriers. The barriers were: unfit mentor-mentee mismatch and ratio; work overload; shortage of qualified staff members to act as mentors; lack of support from mentors and institutions; inadequate time for mentorship programs; lack of mentors' accountability; lack of incentives; negative personality; communication difficulties and external interruptions.

The barriers mentees' reported they majorly encountered during mentorship programs were: inappropriate matching of mentees and mentors; lack of mentors' accountability; shortage of qualified staff members to act as mentors; and lack of support from mentors (Figure 1).

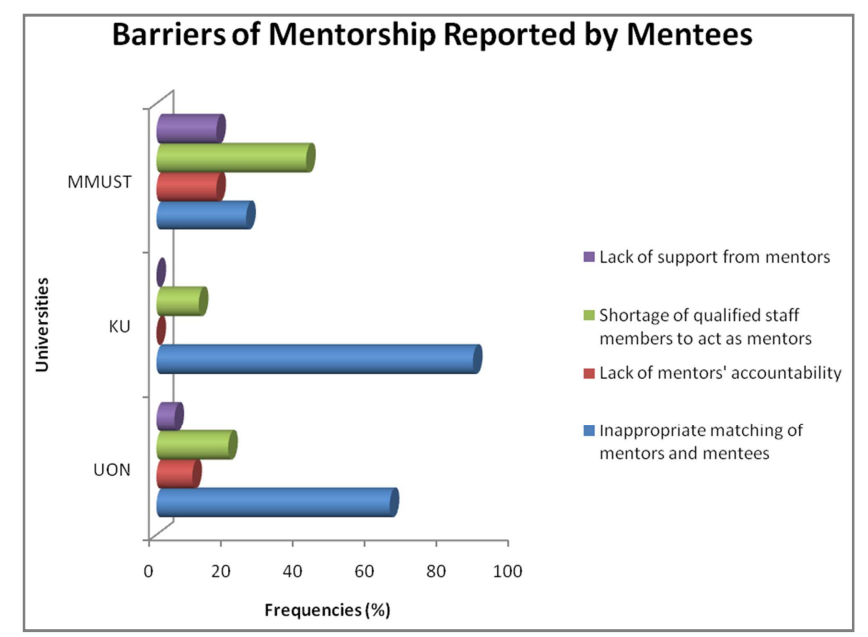

Figure 1. Mentees'report on Barriers of Mentorship Programs.

Mentors reported that the barriers of mentorship programs they majorly faced were work overload, lack of incentives and lack of adequate support from the institutions. Work overload was highly rated (Figure 2).

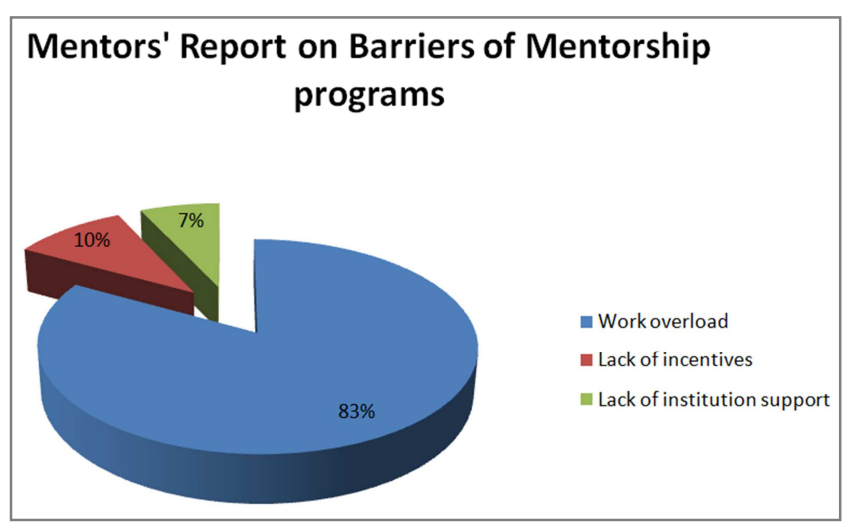

Figure 2. Mentors' Report on Barriers of Mentorship programs.

Unfit mentor-mentee mismatch and ratio

Mentor-mentee mismatch was identified by $75 \%$ ( $n=$ $19 / 25)$ and $87 \%(n=13 / 15)$ of mentees in formal and informal mentorship programs, as a common problem. One 
malementee from KU said that: "Am not comfortable with the mentor l was assigned to, and therefore most of the time $l$ prefers to do my assignments alone without involving her."

While most mentors $(n=85 / 100,85 \%)$, felt the number of mentees they were currently mentoring to be 'too many', a sizable minority $(\mathrm{n}=12 / 100,12 \%)$ considered the number to be 'about right'. Majority of mentors $(n=50 / 58,86 \%)$ in informal mentorship program unlike $(n=15 / 19,78.9 \%)$ in formal mentorship program, complained of mentor-mentee mismatch. Mentors felt that sometimes, they were forced to accept more mentees, even when they had already the required number of mentees. One mentor from $\mathrm{KNH}$ said that: "Sometimes, there were many mentees and not enough mentors to mentor them. We were forced at times to take more than three mentees."

\subsection{Work Overload}

Among the barriers encountered by mentors, work overload was rated highest, $83 \%(83 / 100)$.

One mentor from KNH attested that: "Accident and emergency department is always full with critical patients who need intense care and this poses work overload on us, and most of the times, we cannot engage in mentorship programs."

The work overload was due to staff shortage. Majority of mentors $(n=50 / 58,86.2 \%)$ in informal mentorship programs complained of staff shortage unlike $(n=11 / 19,57.9 \%)$ in formal mentorship programs.

\subsection{Shortage of Qualified Staff Members to Act as Mentors}

Majority of mentees $(n=13 / 15,86.7 \%)$ in informal mentorship programs unlike $(n=17 / 25,68 \%)$ in formal mentorship programs complained of staff shortage. Eighty five percent $(85 \%, n=45 / 53)$ of mentees reported that, nurses who were not through with their training process, and who were not particularly interested in mentor roles, were asked to be mentors, due to staff shortage.

One mentee from KU said that: "Am not supposed to be mentored by a mentor who does not have a BscN, but due to shortage of staff, most of times, these mentors were forced to do it, when we were on their neck."

It was reported by $75 \%(75 / 100)$ of mentors that, nurses who had not been through with their training process, were still asked to take on mentor roles especially in informal mentorship programs.

One mentor from KPGH said that: "Am not supposed to mentor BscN students until l finish my BscN studies, but due to shortage of staff, most of the times, $l$ was forced to do it, when nursing students were on my neck."

More than $80 \%(n=42 / 53)$ of mentees reported that, due to staff shortage, they were used as an "extra pair of hands," which prevented them from being exposed to a wider range of experiences, necessary for them to meet their learning outcomes.

One mentee from KU reported that: "On several occasions, l simply felt like an extra pair of hands. You try to ask questions to enhance your learning, but responses were often brief, and it seemed we inconvenience the nurses who were understaffed with a lot of work. I haven't felt as though clinical placements teach me as much as it should."

Another (77\%, $n=41 / 53)$ of mentees' felt they were pressured by mentors and "pushing them along too fast."

One mentee from UON concurred with this comment and stated that: "They [the mentors] had to rush from one client to the next, pushing us along too fast, and when they finally had time to talk, it was at the end of a busy day when both of us [mentors and mentees] we were tired."

\subsection{Lack of Support from Mentorsand Institutions}

More than sixty five percent $(65.2 \%, n=35 / 53)$ of mentees reported, lack of support from mentors and institutions as another barrier to mentorship programs. One mentee from MMUST attested that: "Due to work overload, mentors did not support us adequately in mentorship programs." One of the supports that $75 \%$ of mentees reported they lacked from mentors was feedback and evaluation. One mentee from UON attested that: "I wonder how our mentors need us to learn from our mistakes, if they do not give us feedbacks..."

Seventy seven percent $(77 \%)$ of mentors in informal mentorship programs reported that, lack of support from the institution caused nursing mentorship programs to suffer from time constrain One mentor from $\mathrm{KNH}$, working in casualty and emergency unit, said that: "Time constraint is our biggest burden; due to lack of the institution support on nursing mentorship programs."

\subsection{Inadequate Time for Mentorship Programs}

Sixty three point three percent $(63.3 \%)$ and $35 \%$ of mentees who practiced in informal and formal mentorship programs respectively reported they frequently encountered inadequate time for mentorship programs. One mentee from $K U$ attested that: "I would wish to meet my mentor and share one or two..., but l cannot! I hate this! Time is frequently inadequate for mentorship programs."

Seventy seven percent (77\%) of mentors in informal mentorship programs reported that, time constrain was one of the barriers that occurred, due to lack of adequate support from the institutions.

One mentor from $\mathrm{KNH}$, working in casualty and emergency unit, said that: "Time constraint is our biggest burden; on a busy shift, we do not always get the chance to explain or give mentees the learning opportunities they needed."

Ninety percent $(90 \%)$ of these mentors added that, nursing students' assessments and documentations, added to their work overload, leading to time constrain. They criticized these as non- friendly.

One mentor who works in maternity ward in KNH said that: "Third trimester which start on May to August is full with nursing students' assessments which also involve documentations. The assessments do run the whole day because we cannot predict when mothers deliver..." 
Time constrains made almost $90 \%$ of these mentors, neither not to attend workshops, seminars and conferences nor conduct researches. Less than a quarter $(15 \%)$ indicated they had attended a workshop, conference and seminar in the last year, and more than $85 \%$ reported not attending them for more than one year. Almost $75 \%$ considered this to be an unmet professional development need, which was important in informing them new changes in nursing profession, improving quality of their services and a way of them getting promotions. One mentor from KNH reported that: "Due to time constrains because of work overload, most of times, we had to forgo workshops, conferences and seminars which were important."

Interestingly, what became evident was that majority $80 \%$ $(n=80 / 100)$ of mentors reported lack of annual updates of mentorship programs especially in informal mentorship programs, because of time constraints. One mentor from UON said that: "Since l joined this university in 2007, there has never been an annual update of mentorship programs, because of time constraints."

\subsection{Lack of Mentors'Accountability}

In UON and MMUST, $80 \%(n=28 / 25)$ of mentees reported lack of clearly defined mentors' accountability. Mentees identified that they did not pair with one consistent mentor. One mentee from UON stated that: "I can't really pair with anyone in particular. I think I have more than four mentors and l finds it difficult in identifying who is accountable to me."

\subsection{Lack of Incentives}

Majority of mentors $95 \%(95 / 100)$ complained that they were not recognized or rewarded for their involvement especially for informal mentorship programs.

One mentor from UON stated that: "We are not treated as though we are valued," while a nurse mentor from $\mathrm{KNH}$ argued that: "We should be recognized for our expertise in mentorship programs. It demoralises us, when no incentives are provided for our efforts despite our busy schedule."

Their suggestions for rewards and recognition included continuing education opportunities, promotions, and enhanced remuneration.

\subsection{Negative Personality}

Eighty percent $(80 \%, n=43 / 53)$ of mentees reported that, negative personality traits affected their mentorship relationships negatively. These personality traits included non-welcoming, impatience, rudeness, proud, lazy, irresponsible, non willingness to take challenges and not innovative.

One mentee from KU complained that: "My mentor was non-welcoming, proud and impatience. I hated encountering with her in many occasions. If it was a must we met, l preferred to be quiet because l did know what would hurt her."

\subsection{Communication Difficulties}

Sixty seven percent $(67 \%)$ of mentors who were involved in informal mentorship programs reported communication difficulties with mentees. This was because of their different ethnic backgrounds. They reported that, more than $80 \%$ of mentees spoke English, but at times, it appeared to lack comprehension. This was attributed to failure to understand local sayings and 'slang' words or culture. Eighty percent $(80 \%, 54 / 67)$ of the above mentors' reported cultural differences, which they were unprepared for and feared causing an offence when correcting them.

One mentor from KPGH said that: "Sometimes when they would say 'yes' I wasn't sure that theyknew what I meant.I would have made a joke out of it. But you can't do thatwith culture difference."

In the context of such experiences, $95 \%$ of these mentors gave mentees information through pre-set agendas rather than responding to their identified needs.

\subsection{External Interruptions}

Finally, $80 \%$ of mentors who were involved in informal mentorship programs reported they encountered difficulties relating to mentees when other people were present. They said that, these people interrupted their exchange of information. One mentor from KPGH reported that: "...when I put a question to her - he answered. She didn't."Also, 40\% of these mentors reported that, relating to mentees posed difficultly when individuals' present did not participate in conversation, despite invitations to do so. Another mentor from KPGH reported that: "Ward managers only sat and listened and I always felt rushed when they were there, whereas if l was only with mentees, we could discuss more."

\section{Discussion}

Barriers mentees' and mentors' reported they majorly encountered during mentorship programs were similar to those reported by Mitchell (2003). According toMitchell (2003); "the barriers were work overload, lack of support, unfit mentor-mentee ratio and matching, unfit personality traits and inadequate time for mentorship programs."

Unfit mentor-mentee mismatch was identified mainly in formal mentorship program. According to Bozeman and Feeney (2008), 'When mentors' and mentees' input were considered during matching, mentor-mentee mismatch was minimised." In this regard, there should be room for views of participants regarding their matching, for any mentorship program.

Unfit mentor-mentee ratio was common in informal mentorship programs. The larger the number of mentees against mentors, the lower the quality of mentorship received by mentees. This was because; the available time was inadequate to mentor all mentees. Higgins and McCarthy (2005), supported the above findings by saying that: "Most mentors $(85 \%)$ in informal mentorship programs argued that, the number of mentees was too large and this was overwhelming." They continued saying that: "Increased 
number of mentees was a factor contributing to increased workload that, rendered mentors less effective."

Work overload was rated highest by mentors. Similarly, Lillibridge (2007), overemphasized that: "Work overload was rated by most mentors $(87 \%)$ as the most prevalent barrier they encountered." Baumann and Chung (2004), further stated that: "Mentors' expressed reluctant to take their roles, because of work overload they had." They continued by reporting that: "Mentors said that their roles slowed them down on their duties and responsibilities, which were already overwhelming." Lastly, Grealish (2009), indicated that: "Most mentors liked to see themselves as promoters of nursing profession, but they were frustrated and disillusioned with their profession's work overload." Due to work overload, mentors did not take their roles or even if they took, they carried it less effectively and this impactednegatively on the learning experiences of mentees.

Due to staff shortage, nurses who were not through with their training process, and who were not particularly interested in mentor roles, were asked to be mentors. This observation was in line with that of Hutchings et al., (2005), who attested that: "Almost $75 \%$ of mentees reported that, due to understaffing, sometimes even non-qualified staff members had to mentor students." When non-qualified staff members and those who were not interested as mentors took part in mentorship programs, there was highly likelihood that mentees could not achieve their learning outcomes, since they could not advocate enough time in mentorship programs.

Mentees were used as an "extra pair of hands." Same observations were reported by Katherine (2003), who said that: "Eighty seven percent $(87 \%)$ of mentees reported that, they were used as an "extra pair of hands" due to staff shortage." Mentees were pressured by mentors and "pushing them along too fast." Similar observations were made by Coleen (2010), who said that: "More than $60 \%$ of mentees said that, staff shortage and work overload caused mentors to push them alone too fast, and thus were unable to meet their objectives." So, institutions' should deal with staff shortage, because it would reduce work overload to mentors, and they would have protected time of mentorship programs, which would necessitate mentees to meet their learning objectives.

Mentees reported lack of support from mentors. Similar findings were reported by Katherine (2003), who attested that: "Eighty percent $(80 \%)$ of mentees reported that, with multifaceted academic and clinical responsibilities, mentors' were pulled in many directions, and they became discouraged to support mentees." Without proper moral and psychosocial support, mentees suffered in their mentorship programs and clearly, this aspect of advocacy was highly valued by mentees. Mentees reported they lacked feedback and evaluation from mentors. Schultz, Kirby, and Delva (2004), supported the above finding by reporting that: "Ninety five point six percent $(95.6 \%)$ of 1,529 medical students surveyed, reported they were not provided with feedback for their learning during mentorship programs by mentors." Another observational study done by Kernan,
Holmboe and O'Connor (2004), also supported the above findings by illustrating that: "Feedback was provided by only $9.4 \%$ of community-based mentors for family and community medicine practice experience." For mentees to develop and improve their skills and knowledge, they needed frequent and regular feedback, which would help them to know what they were doing well, as well as where they needed to improve. High-quality feedback was strongly associated with learners' perceptions of highquality mentorship relationship.

Majority of mentees and mentors who practiced informal mentorship programs encountered inadequate time for mentorship programs. Mitchell (2003), supported the above findings by reporting that: "Almost $70 \%$ of mentees involved in informal mentorship programs complained of frequently encountering inadequate time for mentorship programs." Inadequate time for mentorship programs was frequently encountered because; both dyads were busy with their own tasks and thus, had little time left for mentorship programs, which was not one of their scheduled activity.Mentors reported that nursing students' assessments and documentations, added to their work overload, leading to time constrain.Becker and Neuwirth (2004), supported the above findings by noting that: "Over $85 \%$ of mentors' practising informal mentorship programs, their workload was related to understaffing, large number of critical patients, numerous documentation and assessments for mentees." To sort this problem, universities should employ clinical instructors, who should deal with nursing students' assessments, not nurse mentors.

Time constrains made most mentors, neither not to attend workshops, seminars and conferences nor conduct researches. Same findings were also reported by Mitchell (2003), who argued that: "More than $90 \%$ of mentors in informal mentorship programs did not neither attend workshops, seminars and conferences nor conduct researches." When mentors attended continuous education sessions and did researches, they kept themselves to date with current changes in nursing profession and thus, effectively disseminated current information of nursing profession to mentees without any challenges. There was also lack of annual updates of mentorship programs especially for informal mentorship programs because of time constraints. According to Gagen and Bowie (2005), "Effective mentorship programs extended beyond simply sharing knowledge and skill, but it also entailed annual updates of the programs." Annual updates were important, since they informed mentees and mentors about the progress, new changes, and ups and downs of mentorship programs.

In informal mentorship programs, lack of clearly defined accountability of mentors was reported. Similar findings were reported by Hutchings, Williamson and Humphreys (2005), who said that: "Ninety percent $(90 \%)$ of mentees reported lack of mentors accountability in informal mentorship programs." According to Bozeman and Feeney (2008), "In informal mentorship programs, mentors and mentees were paired naturally. No mentor was accountable to 
a particular mentee." Due to lack of who they were accountable to, mentees' could not fulfil their learning objectives successfully.

Majority of mentors complained they were not recognized or rewarded for their involvement in mentorship programs especially for informal mentorship programs. Grealish (2009), supported the above findings by arguing that: "Eighty eight percent $(88 \%)$ of experienced mentors, who worked in stressful conditions, with continuous staff shortages, complained they were not recognized or rewarded, for their involvement in informal mentorship programs." Mitchell (2003), reported that: "Mentorship being an extra duty for mentors, they needed some rewards or recognition to uplift their morale, which included continuing education opportunities, promotions, and enhanced remuneration."

Negative personality traits affected mentorship relationships negatively. The same findings were reported by Katherine (2003), who said that: "Almost 95\% of mentees reported improper personality traits as a barrier, to smooth running of mentorship programs." Therefore, negative personality traits from either party interfered with mentorship relationships and this should be discouraged.

Communication difficulties were encountered during mentorship relationships. Similar findings were reported by Carey and Weissman (2010), who said that: "Seventy five percent $(75 \%)$ of mentors reported that, in mentorship relationship, there were some forms of communication difficulties because of differences in people opinions, values and norms."

Finally, external interruptions were reported during mentorship process. Similar findings were reported by Mitchell (2003), who attested that: "More than eighty percent $(80 \%)$ of mentors in informal mentorship programs reported encountering external barriers to their exchange of information with mentees, when other members were present." Broscious and Saunders (2005) reported that "Almost $50 \%$ of other parties present during mentorship relationship did not participate in mentor-mentee sharing of knowledge and skill. They were just observant." From this, it seemed, external members who were not part of dyads, were major barriers to mentee-mentor mentorship relationship. It was important that dyads were alone during mentorship programs, to enhance their exchange of information.

\section{Conclusion and Recommendations}

Barriers encountered during mentorship programs were unfit mentor-mentee match and ratio, work overload, shortage of qualified staff members to act as mentors, lack of support from mentors and institutions, inadequate time for mentorship programs, lack of recognition of mentors, unfit personality traits, communication difficulties, and external interruptions. These barriers were highly encountered in informal mentorship programs. They influenced effectiveness of nursing mentorship programs negatively.

For further studies, this study recommended, study to assess relational and reciprocal barriers such as work overload, unfit mentor-mentee ratio, and inappropriate mentor-mentee matching.

\section{References}

[1] Baumann A \& Chung C. (2004). The impact of Health care reform on nursing students clinical performance. USA: Mcmaster Univ.

[2] Becker M. K \& Neuwirth J. M. (2004). Teaching strategy to maximize clinical experience with begining nursing students. Journal of Nursing Education, 41, 89-91.

[3] Bozeman B \& Feeney M. K. (2008). Mentor matching:" a goodness of fit model". Journal of Administration and Society, $40,465-482$.

[4] Broscious S. K \& Saunders D. J. (2005). Peer Coaching. Journal of Nurse Educator, 26, 212-214.

[5] Carey E. C \& Weissman D. E. (2010). Understanding and findings of mentorship. Journal of Palliative Medicine, 13, 73-79.

[6] Cochran W. G. (1977). Sampling techniques (3rd ed ed.). New york: John Wiley \& Sons.

[7] Coleen R. (2010). The role of a mentor in developing a mentee who will work in critical care unit. Journal of Critical Care Nursing, 33, 10-18.

[8] Eby L. T, Butts M. M, Durley J \& Ragins B. R. (2010). Are bad experiences stronger than good onesin mentoring relationships? Evidence from the prot'eg'es and mentor perspective. Journal of Vocational Behaviour, 77, 81-92.

[9] Gagen L \& Bowie S. (2005). Effective mentoring: a case for training mentors for novice teachers. Journal of Physical Education, Recreation and Dance, 76, 40-45.

[10] Grealish L. (2009). Problems facing mentors in theoretical and clinical teachings. Journal of Contemporary Nursing, 19, 37-50.

[11] Higgins A \& McCarthy M. (2005). Psychiatric nursing students' experiences of having a mentor during their first practice placement: an Irish perspective. Journal of Nurse Education in Practice, 5, 18-24.

[12] Hutchings A, Williamson G \& Humphreys. (2005). Supporting learners in clinical practice: capacity issues. Journal of Clinical Nursing, 14, 45-55.

[13] Katherine F. (2003). Mentorship: A critical component for professional growth and academic success. Journal of Dental Education, 68, 324-330.

[14] Kernan W. N, Holmboe E \& O'Connor P. G. (2004). Assessing the teaching behaviours of ambulatory care preceptors. J Acad Med, 79, 1088-1094.

[15] Lillibridge J. (2007). Using mentors to teach leadership and management to senior nursing students. Nurse Educ Pract J, 7, 44-52.

[16] Mitchell G. (2003). Nursing shortage or nursing famine: looking beyond the number. Journal of Nursing science, 16, 19-24.

[17] Schultz K. W, Kirby J, \& Delva D. (2004). Medical students' and residents' preferred site characteristics and preceptor behaviours for learning in the ambulatory setting: a cross sectional survey. BMC Med Educ, 4, 67-89. 